\title{
Service-dominant logic and circular economy - An attempt at integrating two paradigms
}

\author{
Reinhard Weissinger* \\ University of Geneva, School of Social Sciences, 1205 Geneva, Switzerland
}

\begin{abstract}
Based on an analysis of the core concepts of the two paradigms "Service-dominant Logic" (SDL) and "Circular Economy" (CE), this research concludes that the concepts of SDL need to be extended to cover the impacts of the use of material resources and infrastructure which are inseparable from service-forservice exchange. Consequently, SDL's concept of "value" as something entirely subjective and contextual, should be adjusted to reflect the massive impacts of material resource use in service-for-service exchange. The research concludes that an integration between the two paradigms is possible and would be beneficial for both. It would provide SDL with a "sustainability compass" and CE with a set of productive concepts that could be helpful in the identification of areas where service intervention could support more circularity in processes and actor networks and help design and develop service models and practices in support of the transition to a circular economy.
\end{abstract}

\section{Introduction}

Since the publication of the article "Evolving to a New Dominant Logic for Marketing" by Stephen Vargo and Robert Lusch in 2004 [1], Service-dominant Logic (SDL) has evolved to one of the most influential streams in service studies [2]. Starting from an analysis of value cocreating processes between two actors, a provider of a value proposition and a customer, SDL has evolved to a general theory of the market and value creation processes in society that puts service and service-for-service exchange at the center of the analysis. Actors integrate their resources to cocreate value for themselves or another party, they operate as part of larger service ecosystems that can be identified at different levels of aggregation (micro, meso and macro), with their actions being supported but also constrained by institutions (shared actor-created norms, rules, conventions etc.) which may be subject to modification in the course of the interactions. Actors apply operant resources (i.e., skills, knowledge, competencies and technology) on operand resources (natural, manufactured, or other) for the sake of a beneficiary in the process of value cocreation.

Circular economy (CE) has gradually evolved since the 1960s [3]. Over the last decade, it has seen a boost in development and recognition through the support from organizations like the Ellen MacArthur Foundation (EMF), the incorporation into political programs like the European Green Deal (2019) and the Circular Economy Action Plans (of 2015 and 2020) of the European Commission as well as national and subnational policies and programs.

Both paradigms share a holistic and systems-oriented view and for both the creation of value and its retention are central. However, while SDL is focused on value creation through service and the application of operant resources, CE aims at retaining the value of stocks and materials and goods that are flowing through society and the economy for as long as possible and with the highest possible value.

This paper addresses two research questions:

1. Is it possible to integrate the two paradigms?

2. If yes, how could an integrated model look like, and which benefits would result for both paradigms from an integration?

\subsection{Structure of this paper}

The structure of this paper is as follows: In section 2, I introduce SDL as a paradigm that guides a significant stream of service studies by providing an overview of the core concepts that make up SDL. SDL provides on the one side a conceptual framework and, on the other, instruments to analyze "real-world" cases of service entities and processes at different levels, such as organizations, service systems and others. Furthermore, SDL-concepts can be used in service design and the modeling of new or improved service processes and systems.

Towards the end of this section, I extend the discussion and focus on the issue of infrastructure as a wider context that shapes any form of service. While the conceptual infrastructure is part of the current "SDL-toolbox" under the designation

\footnotetext{
${ }^{*}$ Corresponding author: reinhard.weissinger@yahoo.com
} 
of "institutions" (rules, conventions, norms, regulations etc.), the physical or material infrastructure has, with very few exceptions, not been addressed in the SDL-discourse. There is the concept of "operand resources", which are typically environmental inputs, goods etc. in the application of "operant resources" (competencies, know-how, skills etc.). However, the analysis of the dependence of service on a physical and material infrastructure in terms of material flows, energy usage, logistics, transport, telecommunication etc. and the ensuing ecological footprint has not been addressed in the main SDL-discourse. To do this, I propose an extended model that groups SDL concepts into four levels and integrates the previously ignored physical infrastructure into this model.

In section 3, I introduce objectives and core concepts of the Circular Economy (CE). The retention of the value and quality of material stocks and of materials and goods for as long as possible at their highest levels in the economy and society, are main concerns and objectives of the CE. In section 4, I compare the core concepts of the two paradigms and identify commonalities and differences between them. In section 5, I suggest a way of integrating both paradigms that could benefit both of them. Section 6 concludes this paper with a final statement about the benefits of the integration and by answering the two research questions formulated in the Introduction.

\section{Service-dominant Logic (SDL)}

The main sources used in this analysis are publications of Robert Lusch and Stephen Vargo, the originators of SDL, as well as work of other scholars who have closely cooperated and often co-authored publications with Lusch and/or Vargo. My intention is to analyze the theoretical core of SDL, without trying to cover all studies that have tried to apply SDLconcepts to specific cases and subject areas in the "real world" which may have resulted in certain extensions or adaptations of the theoretical core. This internal review of SDL core concepts will identify certain deficiencies that have been left unaddressed by SDL. These deficiencies will then provide the basis for an integration with CE.

\subsection{History and evolution of SDL}

SDL developed through an analysis and critique of what Lusch and Vargo referred to as "Goods-dominant Logic" (GDL) [4], which is still the prevalent paradigm in microeconomics and large fields of economics. According to GDL, companies design and manufacture goods and, in so doing, they are the sole creators of value. Customers then purchase these goods, use them and, in this process, consume and finally destroy value. Goods are at the heart of exchange as they are perceived as the carrier of value which is provided by manufacturers to customers. SDL evolved through the collaboration between Lusch and Vargo "on an initiative to make better sense of the process of value cocreation among actors ..." based on the view that economic exchange "...was more fundamentally concerned with reciprocal service provision, sometimes facilitated by a good" [5].

\subsection{Core concepts of SDL}

According to Lusch and Vargo [6], SDL is based on five core concepts, which are actors, service, resources, value and institutions. I will analyze these concepts below and will add in the analysis another two that are of crucial importance: service ecosystem and innovation. In addition to the core concepts, Lusch and Vargo have formulated 5 axioms and 11 foundational premises of SDL. Where appropriate, I will also refer to some of the SDL-axioms.

The highly generic SDL-concepts are the result of a process which the two authors have described as "zooming-out" ([7-9]) from more specific instances of market interactions. The aim of this process is to arrive at concepts which would be as widely applicable to exchange processes and as independent from specific context conditions as possible. By defining the core concepts at such a generic level, SDL aims at focusing on the foundational aspects of exchange and value creation processes that are common to all such processes and do not depend on any specific conditions.

Actors: In SDL, "actor" is used as a generic concept for all entities (individuals, organizations of different types and complexity) that interact and provide service to each other and, through the exchange of service, cocreate value for each other as beneficiaries. A specific actor can be a producer and a customer. However, even in this example, what these actors do in their interactions is exchanging service for service, i.e., a manufacturer applies know-how in creating value propositions (e.g., a good) for customers, while customers provide other resources (money) in exchange for the utility they can derive in the use of the good. This is expressed in SDL-Axiom 3 which states: "All social and economic actors are resource integrators" ([6], pp. 14).

Service: Service and service-for-service exchange have primacy over goods and the exchange of goods or goods for money. "Service" (singular) is the basis of what is being exchanged between different actors and this is the same in all service exchanges. Irrespective of the specific instance of service, in all service-exchanges resources, such as knowledge and skills from different actors, are applied to (co-)create value for the benefit of another party [8]. Therefore SDL distinguishes between "service" (singular) as common to all exchanges and "services" (plural) as different forms, instances and encounters through which service is being exchanged. Applying terminology from genetics, one could say that the different phenotypes of "services" can all be understood as manifestations of and traced back to a single genotype, which SDL refers to as "service".

Service exchange is based on the application of resources (skills and knowledge and, possibly, also materials) by one party for the benefit of another party or oneself. Service can be direct, e.g., through the skills applied by a teacher, a 
dentist or a repair person, or indirect, e.g., the exchange of money for service. In SDL, goods are perceived as "distribution mechanisms for service provision" [6]. This means goods can be used for the benefit of somebody, but it is only in their use that this benefit occurs. It is not goods for themselves, that have utility, but the service that can be derived from their use. In [10] (p. 47), Vargo and Lusch summarize this view as follows: “... marketing activity (and economic activity in general) is best understood in terms of service-for-service exchange, rather than exchange in terms of goods-for-goods or goods-for-money. In other words, it is the activities emanating from specialized knowledge and abilities that people do for themselves and others (i.e., service, applied abilities) and the activities they want done for them, not the goods, which are only occasionally used in the transmission of this service, which represent the source of value and thus the purpose of exchange."

Resources: SDL distinguishes between two principal types of resources, operand resources that rely on other resources to act on them to provide benefits. Operand resources are often natural resources which, through some form of transformation or processing, become useful for a certain purpose. Other forms of operand resources are goods and tools that require skills and competences for their use. The other type of resource are operant resources, which refer to competencies, skills, knowledge, capabilities that are applied to cocreate benefits for other parties. In the example with natural resources, operant resources are applied as skills, but also in the form of technology $([11,12])$ to transform natural resources into something of use to actors. In terms of access and ownership of resources, the following three types can be distinguished ([8], pp. 127): Public resources, market-facing resources and private resources, which are often combined in resource integration. Lusch and Vargo ([8]) claim that resources "become" ([13,14]) which means through the combination of skills, knowledge and technology (i.e. operant resources), operand resources can be used or transformed for purposes which may not have been possible at an earlier point in history. To express this dynamic relationship and characteristic of resources (operant and operand) Lusch and Vargo ([8], pp. 124) introduced the term "resourceness".

Value: Different from this perspective of GDL (see 2.1), SDL considers that value is not created by a single party, but cocreated by multiple actors that form ecosystems of interactions, use their competencies, integrate resources and jointly create value. Service and the application of resources for the benefit of other actors is seen as the basis of the interaction between actors. Actors contribute their skills and know-how and exchange it for service provided by other actors. In this sense, interaction does not occur as an exchange of goods, but in the form of service-for-service exchange.

While GDL looks at value being created for sales, i.e., the exchange of goods for money, SDL holds the view that value exists only in use, i.e., when a value proposition offered by a manufacturer, is actually used by an actor then that service contributes to improving the condition of the final user as the beneficiary of the service ([15]). Goods are understood as "distribution mechanisms for service provision" ([6], p. 10), they are not valuable in themselves but only in the utility that can be derived from their use.

The different locations of value creation versus cocreation along a generic value chain between the two approaches are shown in the Figure 1:

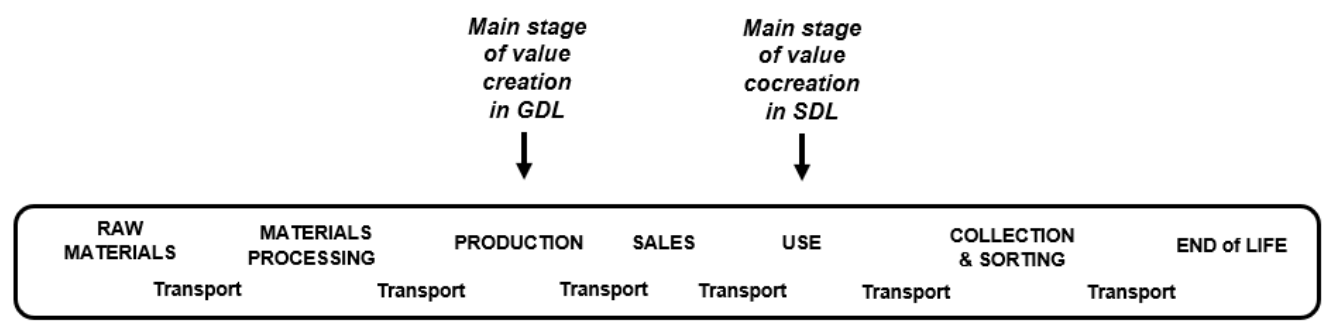

Value-in-Exchange

Value-in-Use

Fig. 1. Generic value chain - Comparison between value creation in GDL and cocreation in SDL. Source: Author's figure

The creation of value is the purpose of exchange and value results from the application of resources by different actors. Value is cocreated and is realized as benefit for another actor or actors in their practice. SDL-Axiom 2 on value cocreation states: "Value is cocreated by multiple actors, always including the beneficiary" and value is "... not created by one actor alone and then subsequently delivered" to a customer or beneficiary ([10], p. 47).

Another important point is that in SDL, value is considered to be subjective, actor-specific and context-dependent, i.e. it exists from the perspective of a beneficiary and is therefore not independently measurable ([16]). SDL-Axiom 4 states: "Value is always uniquely and phenomenologically determined by the beneficiary" ([6], p. 15).

Institutions: Institutions are rules, norms, conventions, legal regulations etc. that have been created by actors, are shared between them and apply to actor-to-actor cooperation and interactions. As structuring elements, shared institutions or institutional arrangements facilitate the cooperation between actors and provide orientation between them but also 
restrict options for the interactions. Through interaction between various actors, institutions are themselves subject to revisions, modifications over time or disruptions etc. Axiom 5 in SDL states: "Value cocreation is coordinated through actor-generated institutions and institutional arrangements" ([6], pp. 15).

Service ecosystem: Actors do not exist in isolation but are embedded into networks through which they cooperate and interact regularly on the basis of shared institutions. Lusch and Vargo ([8], p. 161) define a service ecosystem as "A relatively self-contained, self-adjusting system of resource-integrating actors that are connected by shared institutional logics and mutual value creation through service exchange" and Lusch and Nambisan ([17] p. 162), slightly differently, as a "A relatively self-contained, self-adjusting system of mostly loosely coupled social and economic (resourceintegrating) actors connected by shared institutional logics and mutual value creation through service exchange". Service ecosystems typically emerge from the interaction of actors who, during their interaction, form networks, i.e. evolve into more complex structures which again transform into structures with a certain stability, which are referred to as service ecosystems ([7], 2009). These relate to each other on the basis of institutions and institutional arrangements that define the rules and practices of the cooperation between different actors and different ecosystems. Service ecosystems are dynamic, they can re-configure, are often open to new entrants which allows the integration of previously unavailable resources provided by them. Service ecosystems can extend and change, but they can also shrink in case actors re-orient their activities and engage in the collaboration with other or new actors.

Service ecosystems exist at different levels of aggregation and are nested ([6,8]). They feed, interact with and provide structure for each other. In SDL, a distinction has been made between a micro level (e.g. a product, a firm or a group of firms), a meso (e.g. an industry sector) and a macro level (e.g. a large region, nation state or beyond).

As acknowledged by Lusch and Vargo, the focus on the interaction between different actors, the integration of resources by them provided by various actors and the cocreation of value through multiple actors, triggered a significant shift in the understanding of "...the orientation among actors, away from the primacy of conflict and toward the primacy of cooperation and coordination" ([10], p. 49).

Innovation: Lusch and Nambisan ([17], p. 161) define: "Service innovation can then be considered the rebundling of diverse resources that create novel resources that are beneficial (i.e., value experiencing) to some actors in a given context; this almost always involves a network of actors, including the beneficiary (e.g., the customer)." Actors operate in dynamic service ecosystems and integrate their various resources through cooperation. In this process new configurations can emerge, and resources are integrated in new forms. Innovations, different from inventions, are not only the result of scientific-technological processes of discovery, but rely also on market-shaping actors that help inventions "to gain institutionalization" by changing or disrupting existing institutional arrangements, practices and behaviour ([8], p. 209; [18], [19]).

In summary, SDL has evolved through a process which Lusch and Vargo describe as "Zooming-out", i.e. a progressive abstraction from specific conditions of market exchanges towards the development of a set of highly generic and interrelated concepts that can be applied widely for the analysis of market interactions as well as for the design of service systems. As seen by SDL, service systems are based on the interaction between a multitude of resource-integrating actors who cooperate in often complex service ecosystems with the aim of cocreating value for themselves and for each other. To do this, they apply and integrate competences, knowledge and technology, i.e. operant resources, and use - as needed - operand resources, which are often natural resources, tools, goods or other instruments. To ensure success of the interactions between multiple actors, their actions need to be coordinated and integrated through an "architecture for participation" ([17], p. 165) and institutional arrangements that exist as conventions, rules, regulations or norms in society and which are further evolved in the negotiations by the actors and/or emerge during the practices of cooperation. Institutional arrangements provide support and structure for the interactions and - at the same time - are subject to changes and improvements, which often result in innovative solutions and new forms and constellations for service provision.

\subsection{Discussion: Embedding SDL in a wider context}

In this subsection I will discuss SDL by reviewing the role of the physical or material infrastructure for service exchange and analyzing the dependency of service on this infrastructure.

\subsubsection{Resources, physical infrastructure and material impacts of service exchange}

As introduced in section 2.2, SDL distinguishes between two types of resources: operand and operant. By applying the latter on the former, value propositions are created by actors (typically firms). While it is possible to apply this generic description of resource generation, integration and use to the different stages of a generic value chain model (see Figure 1), such a description does not adequately account for the massive ecological impacts of current infrastructure, production and consumption systems around the world.

As a consequence of the generic description in SDL, value is conceived to be entirely subjective and dependent only on the perception of the beneficiary (see SDL-Axiom 4). In consideration of the significant environmental impacts (in terms of resource use, emissions and health impacts), but also the social impacts (e.g. in terms of labour conditions in international supply chains), the concept of value as being entirely subjective, seems to be inappropriate. Obviously, if 
value is subjective and environmental and social concerns do not rate high in the ranking of potential beneficiaries (i.e. customers), then incentives for firms to transform their production systems and resource use towards more sustainability are weak which in turn reinforces current unsustainable infrastructure, production and consumption systems.

One reason for this deficit seems to be that there has not been much discussion in SDL of infrastructure, large-scale service systems and their social and environmental impacts. One exception is an article by Wieland et al ([20], p. 18), that states "Complex service systems are everywhere (from healthcare to traffic management, from smart power supply to food production, from telecommunications to waste management) and their performance impact the service experience of all human actors. Hence, an increased understanding of the underlying logics of these complex systems is necessary to further advance the frontiers of service research....". These complex systems rely on large-scale material infrastructure which imposes choices in terms of energy use, material inputs, modes of use and operations and therefore impact the way service actors can interact, integrate their resources, organize service processes and provide value propositions to customers. In spite of the recognition of the importance of complex service systems and material infrastructure more generally, this insight by Wieland et al. did not influence the subsequent development of core concepts in SDL. Other streams of service research, however, have addressed this aspect $([21,22])$.

Fulmer [23] defines infrastructure as "The physical components of interrelated systems providing commodities and services essential to enable, sustain, or enhance societal living conditions." Thacker et al [24] state: "Infrastructure systems form the backbone of every society, providing essential services that include energy, water, waste management, transport and telecommunications. Infrastructure can also create harmful social and environmental impacts, increase vulnerability to natural disasters and leave an unsustainable burden of debt."

A distinction is made between "hard" and "soft" infrastructure. UNEP ([25], p. 10) defines infrastructure systems as comprising "... physical assets (also referred to as hard infrastructure) plus the knowledge, institutions and policy frameworks (also referred to as soft infrastructure) in which they exist and that enable them to function. These include both built, or grey, infrastructure in all sectors, and natural, or green, infrastructure" (highlighted in the original).

Infrastructure underpins all social and economic activities of actors. Activities are undertaken on the basis of the existence of certain infrastructural conditions whose existence make certain actions possible. Examples are obtaining water through large-scale water supply systems, travelling places by car or plane which rely on a road or transport infrastructure and the provision of energy or accessing data from a server system somewhere in a cloud, an activity which relies on complex data storage, communication and energy supply systems.

Resource integration by multiple actors for value cocreation, depends to a significant extent on existing large-scale infrastructure and production systems. Using SDL-terms, infrastructure systems - as a form of technology - can be considered to represent operant resources $([10,12])$. Technology, “... including, but not limited to, its material manifestation, should be considered operant resources." ([12], p. 727). To operate, renew, maintain and possibly extend existing infrastructure, requires massive natural resources, such as water, fuel, minerals, metals, energy, i.e., large amounts of different operand resources.

Infrastructure generates therefore ecological footprints which, to a large extent, are pre-determined and therefore outside the choice of any individual actor at a given point in time.

It is widely acknowledged that the global patterns of current production and consumption generate significant externalities in the form of climate change ([26]), extensive resource use ([27,28]), biodiversity loss ([29]) and pollution ([30]) which increasingly threaten life on this planet. In the core texts of SDL, hardly any references exist to these aspects of material impacts that are linked to service exchange. The only exception is a very brief reference to the existence of ecosystem services by Lusch and Vargo themselves ([8], p. 173). As an in-depth study, Matthies et al [31] address ecosystem services and SDL in the context of natural systems. However, I do not consider this paper part of the "core texts" of SDL as defined in section 2. There is also no evidence that it had an influence on the further development of SDL's core concepts.

\subsubsection{The concept of "value" in SDL}

In SDL "value" is understood as “... benefit, an increase in the well-being of a particular actor" ([8], p. 57, highlighted in the original). Value is seen as "...always uniquely and phenomenologically determined by the beneficiary" ([8], p. 78) and understood as "actor specific", "contextually distinct" with the consequence that "every occurrence is unique" ([8], p. 57). This means that "value" only exists as perceived by the benefitting actor(s) and is therefore entirely subjective.

However, in consideration of the massive environmental impacts (in terms of resource use, emissions and health impacts), but also social impacts (e.g. in terms of labour conditions in international supply chains), the concept of value 
as being entirely subjective seems to be inappropriate. If significant environmental damage is caused for the production of value propositions (e.g. in the form of goods), then this aspect should be reflected in the concept of value.

\subsection{Conclusions from this discussion}

I draw the following two main conclusions:

Conclusion 1: The material basis of resource integration, which relies on large-scale infrastructure production and consumption systems, has significant environmental and social impacts on service provision. It needs therefore to be acknowledged and included in the analysis. Actors are not free to organize their interactions and resource integration processes outside of existing infrastructure systems. Operating within this infrastructure is the way how interaction between actors in today's economy and society works. It is therefore important to extend the horizon and incorporate the material context into SDL.

Resulting from this discussion, I propose, as shown in Table 1, an extended model of SDL that groups SDL core concepts into three interrelated levels (L2 to L4), and adds a foundational level (L1), representing the physical infrastructure, on which the three levels of service interactions are based.

Table 1. Extended model of SDL.

\begin{tabular}{|c|l|l|l|}
\hline $\mathbf{1}$ & Level & Content of the level & This includes: \\
\hline $\mathbf{L 4}$ & $\begin{array}{l}\text { Service-for-Service exchange instances: based on resource integration } \\
\text { and value cocreation between and by different actors }\end{array}$ & $\begin{array}{l}\text { A2A-interaction, } \\
\text { resource integration, } \\
\text { value cocreation }\end{array}$ \\
\hline \multirow{2}{*}{ L3 } & $\begin{array}{l}\text { Service ecosystems: multi-layered dynamic systems that provide } \\
\text { structure and integrate actions of different actors }\end{array}$ & $\begin{array}{l}\text { Structures for A2A- } \\
\text { interaction, resource } \\
\text { integration }\end{array}$ \\
\hline L2 & $\begin{array}{l}\text { Institutions, "soft" or conceptual infrastructure: shared systems of rules, } \\
\text { codes of conduct, conventions, standards, regulations etc. }\end{array}$ & $\begin{array}{l}\text { Shared rules etc. form } \\
\text { constituent elements of } \\
\text { service ecosystems }\end{array}$ \\
\hline L1 & $\begin{array}{l}\text { Physical infrastructure, "hard" or material infrastructure: physical } \\
\text { systems for material resource flows, production and consumption } \\
\text { systems; energy systems; transport and communication infra-structure; } \\
\text { built environment; end-of-life disposal systems etc. }\end{array}$ & $\begin{array}{l}\text { Extension of SDL to } \\
\text { reflect the dependence } \\
\text { of service on the } \\
\text { physical and material } \\
\text { infrastructure }\end{array}$ \\
\hline
\end{tabular}

The four levels in the model can be read either in bottom-up or top-down direction. Starting bottom-up (L1 to L4), we begin with the foundational role played by physical, material or "hard" infrastructure as level 1 (L1) and move up to level 2 (L2) with institutions and institutional arrangements ("soft" infrastructure) which comprises rules, conventions, norms, regulations etc. Above these two levels follow multi-layered service ecosystems at level 3 (L3) and service exchange instances (L4). The extension to SDL resides at L1, whereas levels 2 to 4 comprise the SDL-core concepts introduced in section 2.2. We can also move in top-down direction (L4 to L1) through the four levels based on their different degrees of visibility: L4, the most visible level, comprises interactions between actors for the purpose of value co-creation and can be observed on a day-to-day basis in the form of social and business transactions. Further analysis shows that transactions between actors are not simply spontaneous but reliant on dynamic structures or interaction networks, which provide a certain stability, but evolve and reconfigure over time, termed "service ecosystems" (L3). Service ecosystems again rely on rules, conventions etc. which are partially generated directly between the actors residing within the same or connected ecosystems. Another more foundational source of these rules are laws, regulations, codes of conduct etc. that have been developed by legislative or rule-setting bodies and which apply to business and social interactions in general and to all societal or economic actors. These rules are integrated as reference frameworks into service ecosystems but do not origin within them. This level, L2, is represented by institutions or "soft" or conceptual infrastructure. Finally, we arrive at L1, the underlying physical, material or "hard" infrastructure of material stocks and flows, which forms the foundation of all societies and economies, including markets and the service space which depends on this level.

I am not suggesting that L1 is specific to SDL. L1 represents the basic conditions under which society and the economy operate. What I am suggesting is that SDL should account for the material impacts of service by acknowledging the material dependency of service on L1.

Conclusion 2: Service-for-service exchange aims at cocreating value. Besides generating economic value, which is measured in market prices (i.e. exchange values), ecological footprints ([32]) are generated. Significant damage, waste or "negative value" is created during resource integration due to the way resources are integrated between actors under the conditions of today's infrastructure, technology, choice of energy etc. This aspect of "value" is not subjective but exists 
independent of the perception of the actors affected. It can be assessed with different methodologies, some of which even support monetary valuation of incurred damages and value loss.

As shown in Figure 2, "value" should therefore be perceived as having two main aspects: (1) one which is subjective, specific and determined by the beneficiary (as defined in SDL-Axiom 4) which I call "value to beneficiary" and (2) a second aspect, which I refer to as "value to society" which occurs in two principal forms: (a) as economic value expressed through market prices or exchange value and (b) as ecological footprint or ecological impacts. The latter results either from unintended consequences of how value is currently created, from institutional arrangements that permit such practices or as an "unavoidable" outcome of current infrastructures, resource use, technology, models of operation and other conditions. It is typically negative and may therefore severely reduce the economic value produced, if adequately accounted for. However, footprints are typically not or only partially reflected in market prices so that it is easy to ignore or overlook them. This does not exclude the fact that value propositions in product offerings contain in many cases "green", "organic" or "sustainable" value components [33] which appeal to many consumers as a way towards a more "responsible" consumption. Whatever the substance of such claims in individual cases, these offerings aim at appealing to the personal or subjective preferences and values of customers and fall therefore into the category of "value to beneficiary". Only a systematic reflection of ecological footprints of all or most products and materials in their prices (which may include the need to apply e.g. taxation to increase prices if market mechanisms are insufficient) would ensure that the full and objective value of products and materials is expressed in their market prices.

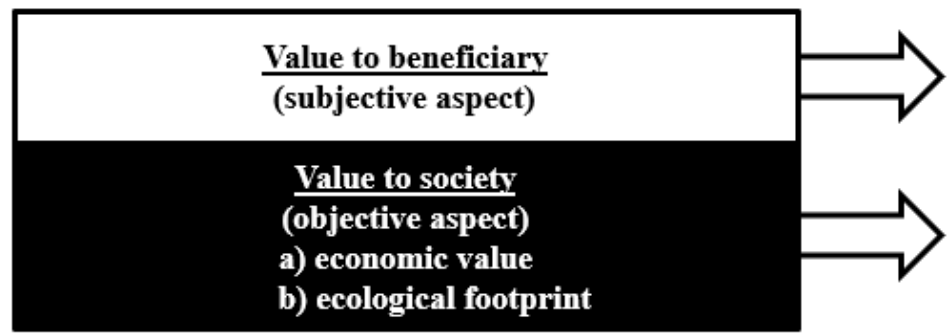

Subjective aspect:

Not measurable, determined by personal preferences \& context

Objective aspect:

Measurable, determined by

a) market prices and

b) ecological footprint

(often without market value)

Fig. 2. The two aspects of value.

Source: Author's figure

Ecological footprints differ significantly between countries and different social and income groups ([34]). However, it is undisputed that globally, the current ecological footprint significantly exceeds the planet's capacity to replenish [32], [35]. As an example, the most recent Circularity Gap Report 2022 states that since 2015 “... the global economy consumed $70 \%$ more than what the Earth can safely replenish" [36]

\section{Circular economy (CE)}

In this part I give an overview of the history, the objectives and some of the core concepts of the CE to prepare for a comparison between the two paradigms in section 4 .

\subsection{History and evolution of the CE}

CE has gradually evolved since the 1960s starting with the publication of Boulding's paper "The economics of the coming spaceship earth" [3]. In this paper Boulding compares the present world to a closed system (i.e. a "spaceship") without inputs from the outside, except for energy from the sun, which needs to rely on the finiteness of its resources. The key concern under such conditions is therefore the maintenance of natural stocks to avoid their degradation and possible extinction.

In 1987 Stahel and Reday-Mulvey introduced the concept of "closed loops" through which materials are retained in the economy and waste is transformed into resources for subsequent industrial processes [37]. The term "circular economy" was introduced in the book "Economics of natural resources and the environment" by Pearce and Turner, which was published in 1990 [38]. This book also uses the concept of the current economy as a linear system which, by integrating the environment as a life support system into the economy, becomes transformed into a circular system.

As mentioned in section 1, CE has recently seen a boost in development and recognition through the support from organizations like the Ellen MacArthur Foundation (EMF) and the European Commission. It has been adopted in national and subnational action plans (e.g. in city development plans) in many countries, ranging from Europe to Japan and China and countries in North and South America. Ghosh's global overview of the CE [39] contains studies from 21 countries or regions across the world that engage - to different degrees - in CE initiatives. 


\subsection{Objectives and core concepts of the CE}

There is a large number of publications about CE with various definitions and explanations. [40], [41], and similarly [42] refer to CE therefore as an "umbrella concept" which encompasses various pre-existing concepts, such as industrial ecology, industrial symbiosis, cradle-to-cradle, eco-design, life cycle thinking, functional economy, shared value, sustainable development and others. Kirchherr et al. [43] collected a total of 114 different definitions of the term "circular economy" for their analysis.

As an umbrella concept, CE combines and extends some of the earlier concepts and creates a new space for research, policy, social development and business. However, as a consequence, the concept becomes to a certain degree ambiguous and fuzzy with blurred boundaries and has been criticized for these and other deficits ([44], [45]). Unlike in the case of SDL, the analysis below is therefore based on a synthesis of a variety of sources and contributions and may not reflect the view of all authors who have contributed to CE-research.

\subsubsection{Objectives of the $C E$}

The objectives of CE have been defined by Webster ([46], p. 17) as an economy "...that is restorative by design, and which aims to keep products, components and materials at their highest utility and value, at all times." A more recent definition of the objective of a CE is given on the EMF-Website: "A circular economy seeks to rebuild capital, whether this is financial, manufactured, human, social or natural. This ensures enhanced flows of goods and services.” ...[T] he continuous flow of technical and biological materials ..." can be represented "... through the "value circle"”. Stahel ([47], p. 1) states: "The objective of the circular economy is to maintain the values, and manage stocks, of assets, from natural, cultural, human, manufactured to financial stocks." CE is generally seen as an important approach towards the transition to a sustainable economy and society [48].

\subsubsection{Core concepts of the CE}

In the following I give an overview of core concepts of the CE.

Circular directionality: Typically CE is characterized as a counter-model of the dominating "linear economy" (LE) which is often referred to as a "take-make-dispose" economy (see Figure 3). CE operates with closed loops to ensure resources are continuously used and not wasted. To ensure this, CE is built on circular directionality. This means a deliberate attempt to retain all forms of assets for as long and with a quality as high as possible and by avoiding waste or uncontrolled emissions into the environment.

\section{Linear economy}

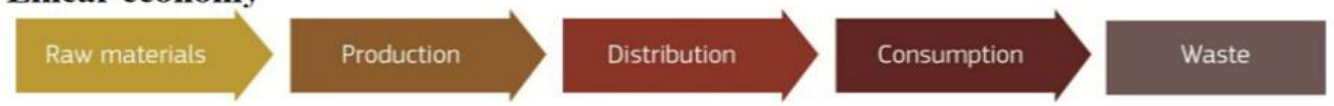

\section{Circular economy}

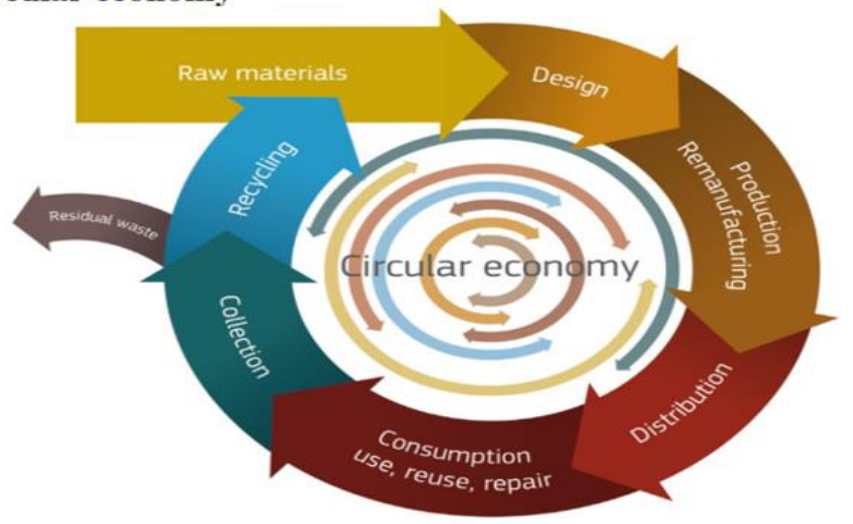

Fig. 3. The linear (LE) versus the circular economy (CE).

Source: European Commission [49], p. 5

Maintenance of stocks, efficiency of the use of materials and products, avoidance of waste: CE is an industrial system which is "restorative" or "regenerative" and "avoids waste by design". It aims to achieve resource efficiency, closed loop cycles and keeps materials and goods in use at their highest utility and value in the long term. To achieve this objective, it is of key importance to maintain the quality and quantity of stocks and avoid their overuse [47].

Operational strategies ("R-strategies"): The CE aims at reducing inputs and strives to use materials and energy as efficiently as possible. The life cycle of products is extended through initiatives such as repair, reuse, refurbishment and 
remanufacturing, i.e. short loops. Recycling, a long loop which results in the loss of the utility of the original product and its embedded energy, is of key importance, though a less preferred option. In earlier work on the CE a distinction was made between 3 Rs: Reduce, Reuse and Recycle, which was later extended to 10 Rs ([41]).

Table 2. The 3 Rs.

\begin{tabular}{|l|l|}
\hline R1 & Reduce \\
\hline R2 & Reuse \\
\hline R3 & Recycle \\
\hline
\end{tabular}

Table 3. The 10 Rs classified by loop types.

\begin{tabular}{|l|l|l|}
\hline R0 & Refuse & Shortest Loops \\
\hline R1 & Reduce & Shortest Loops \\
\hline R2 & Resell/Re-Use & Shortest Loops \\
\hline R3 & Repair & Shortest Loops \\
\hline R4 & Refurbish & Medium Long Loops \\
\hline R5 & Remanufacture & Medium Long Loops \\
\hline R6 & Repurpose & Medium Long Loops \\
\hline R7 & Recycle Materials & Long Loops \\
\hline R8 & Recover (energy) & Long Loops \\
\hline R9 & Re-mine & Long Loops \\
\hline
\end{tabular}

Design: A key function towards ensuring reuse and the reduction of waste during a typical product life cycle is design or eco-design (Figure 4 shows the difference between eco- and traditional design in terms of addressed life cycles stages). It is claimed that over 80 percent of environmental impacts are determined in the design stage of a product ([42]). Therefore adequate and optimized design choices, improvement of the quality of the chosen materials that go into products (e.g. the avoidance of toxic materials, which would impede reuse or recycling) and modular design approaches, which increase the repairability and reusability of products, can all contribute to extending product lifetime.

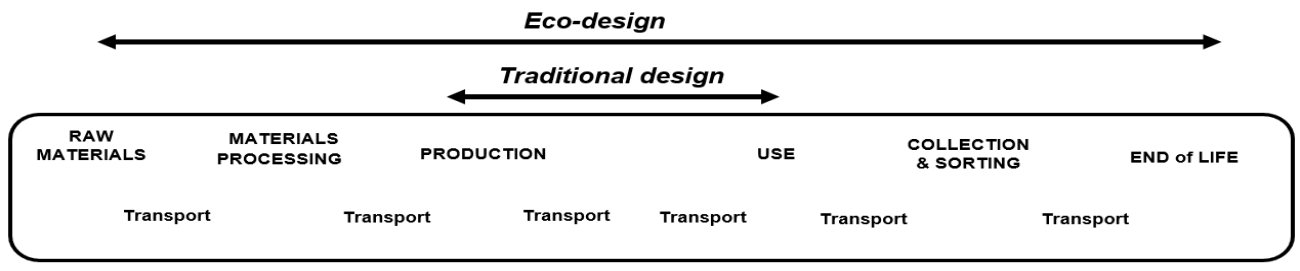

Fig. 4. Adapted from: Eco-design versus traditional design, Source: [50], p. 550

Energy use: Preference is given to the use of renewable energy sources which decreases environmental impacts.

Different levels or layers of the CE: Typically a distinction is made between three different levels or layers of the CE, i.e. a micro-level (e.g. individual products, companies), a meso-level (groups of interacting companies e.g. in industrial parks) and a macro-level (cities, nations or even larger entities). CE can be addressed at very different levels and contexts which range from individual products to nation states or beyond.

Decoupling between economic growth and resource use: To overcome, avoid or significantly reduce detrimental impacts on the environment in the form of accelerating climate change, biodiversity loss and pollution, circular economy aims at decoupling value creation from waste generation and resource use by radically transforming production and consumption systems $([27,47])$. Decoupling concepts aim for absolute decoupling, i.e. growth in output with a simultaneous reduction of resource inputs.

Extensive cooperation: As current production systems are fragmented in highly complex supply chains, CE requires improved planning and coordination between economic and societal actors who contribute jointly to CE objectives by following shared principles, rules, architectures and standards and are prepared to contribute their specific know-how.

Business models: Business models in $\mathrm{CE}$ focus on the extension of product use and the performance or the utility of products but not their ownership. Stahel [51] speaks of the "Performance Economy" in which customers purchase the right to use but not the ownership of goods. Business models are often based on the principle of extended producer responsibility (EPR) whereby the producer retains ownership over the full use cycle of a product, is responsible for maintaining its functionality and is therefore interested in extending its lifetime. A user does not pay for a product but for access to the service that derives from the use of the product ("Product as a Service" - PaaS, "Mobility as a Service" - 
MaaS or, more generally, "X as a Service" - XaaS). Other models focus on the shared use of products (e.g. cars, washing machines etc.) by several persons each of whom would typically use a product only for a short period of time ([52]).

Value creation: In CE value is created through the cooperation and interchange between market actors in processes. Value is increased through more intensive use of resources, the avoidance of or re-use of waste as a resource for other processes and companies, product lifetime extensions, cascading use of resources, re-entering of products at their end of use in second-hand markets or, after remanufacturing, back into production and, as a final option, recycling and re-use of secondary raw materials ([42]). Waste, which remains permanently unused and is not converted into a new resource, is perceived as lost value.

\section{Comparison between the two paradigms}

In this section I compare the core concepts of the two paradigms, CE and SDL, identified in the sections 2.2 and 3.2.2 and map them to each other with the intention to determine commonalities and differences.

In Table 4, I cluster the concepts into three main groups: (1) concepts related to the basic structure of each paradigm, (2) concepts related to their main objectives and (3) concepts related to strategies/means that are of key importance for both paradigms to achieve their objectives. Since I have chosen the CE-concepts as the basis, I list sample references to texts from the SDL-core literature to provide evidence of the occurrence of these or closely related concepts.

Table 4. Mapping between CE core concepts and related SDL core concepts.

\begin{tabular}{|c|c|c|c|c|}
\hline $\begin{array}{l}\text { Categories } \\
\text { (category groups } \\
\text { in bold) }\end{array}$ & $\#$ & CE-Concepts & $\begin{array}{l}\text { Corresponding or related } \\
\text { SDL-Concepts }\end{array}$ & $\begin{array}{l}\text { Main sources in SDL- } \\
\text { literature }\end{array}$ \\
\hline \multicolumn{5}{|l|}{ 1.Structure } \\
\hline Structure & 1 & (Circular) Directionality & - & \\
\hline Structure & 2 & $\begin{array}{l}\text { Multi- (three) level structure in } \\
\text { CE (micro, meso, macro) }\end{array}$ & $\begin{array}{l}\text { Multi- (three) level structure } \\
\text { of Service ecosystems } \\
\text { (micro, meso, macro) }\end{array}$ & {$[6,8]$} \\
\hline \multicolumn{5}{|l|}{ 2. Objectives } \\
\hline Objectives & 3 & Maintenance of stocks & - & \\
\hline Objectives & 4 & Efficiency of material use & $\begin{array}{l}\text { Resources (efficiency): } \\
\text { Resourceness as an } \\
\text { application of operant on } \\
\text { operand resources }\end{array}$ & {$[8,17]$} \\
\hline Objectives & 5 & $\begin{array}{l}\text { Reduction or avoidance of } \\
\text { waste }\end{array}$ & $\begin{array}{l}\text { Resources (efficiency) : } \\
\text { Resourceness as an } \\
\text { application of operant on } \\
\text { operand resources }\end{array}$ & {$[8,53-55]$} \\
\hline Objectives & 6 & $\begin{array}{l}\text { Efficiency of energy use } \\
\text { (renewables) }\end{array}$ & - & \\
\hline Objectives & 7 & $\begin{array}{l}\text { Value creation / Value } \\
\text { retention (through resource } \\
\text { efficiency and decoupling) }\end{array}$ & Value cocreation & {$[6,8]$} \\
\hline Objectives & 7.1 & Value-in-use & Value-in-use & {$[8]$} \\
\hline Objectives & & - & $\begin{array}{l}\text { Value to beneficiary } \\
\text { (subjective value) }\end{array}$ & {$[6,8]$} \\
\hline Objectives & 7.2 & $\begin{array}{l}\text { Economic value (one aspect of } \\
\text { objective value) }\end{array}$ & Value-in-exchange & {$[6,8]$} \\
\hline Objectives & 7.3 & $\begin{array}{l}\text { Ecological footprint (one } \\
\text { aspect of objective value) }\end{array}$ & - & \\
\hline \multicolumn{5}{|l|}{ 3. Strategy/Means } \\
\hline Strategy/Means & 8 & $\begin{array}{l}\text { Decoupling (growth from } \\
\text { resource use) }\end{array}$ & - & \\
\hline Strategy/Means & 9 & $\begin{array}{l}\text { Operational strategies ("R- } \\
\text { strategies") }\end{array}$ & - & \\
\hline Strategy/Means & 10 & $\begin{array}{l}\text { Extensive cooperation } \\
\text { (between different actors) }\end{array}$ & $\begin{array}{l}\text { Actors / Resource integration } \\
\text { / Institutions }\end{array}$ & {$[6,8]$} \\
\hline Strategy/Means & 11 & Business models & $\begin{array}{l}\text { Actors / Resource integration } \\
\text { / Institutions / Innovation }\end{array}$ & {$[56,57]$} \\
\hline Strategy/Means & 12 & Innovation, Design & $\begin{array}{l}\text { Actors / Resource integration } \\
\text { / Innovation / Value } \\
\text { cocreation }\end{array}$ & {$[8,18,55]$} \\
\hline Strategy/Means & 13 & - & $\begin{array}{l}\text { Service is the basis of all } \\
\text { exchange }\end{array}$ & {$[6,8]$} \\
\hline
\end{tabular}




\subsection{Commonalities between CE and SDL}

It is evident from Table 4, that there is significant but not complete commonality between core concepts of the two paradigms in all three category groups: In particular in the group "Objectives" both paradigms emphasize efficiency of resource use and avoidance or reduction of waste and for both the concept of "value" is key. However, SDL is focused on a subjective notion of value (which has no conceptual equivalent or relevance in CE, except e.g. in consumer behaviour and consumer psychology). In CE, value is an objective concept related to extending resource use for as long as possible and maintaining in particular resource stocks, which is not addressed in the core SDL-literature (with, as already mentioned, the single exception of Matthies et al [31]).

Regarding "value", both paradigms emphasize value-in-use which enables the development of business models that provide desired utility independent of the transfer of ownership of goods, but, e.g., through service models ("product as a service) ([57]) or through what Stahel ([51]) calls the "performance economy".

In both paradigms, extensive cooperation between different actors, the use and integration of their competences ("resources") is key, which results in innovation and - over time - changes in the ecosystems in and through which the actors interact. Combined with the emphasis on use-value (instead of exchange-value), dynamic service ecosystems can lead to the emergence of multiple forms of business models and institutional re-arrangements which do not rely on ownership as a precondition. This provides an opportunity for the development of a multitude of service models and modes of service interaction between actors.

\subsection{Differences between CE and SDL}

However, there are also major differences between the two paradigms: Perhaps the most important difference is the circular directionality which is at the heart of CE. Although SDL sees actors, ecosystems and their relationships as dynamic, no overall directionality exists in SDL. Actors cocreate value for beneficiaries, but without an overarching orientation towards building a socioeconomic system that is based on a balance between available stocks of materials and energy sources on the one side and their flow and use in production and consumption by society on the other. For CE, economic and societal activities have to be re-oriented and re-designed towards a circular structure as a precondition for long-term sustainability.

Another difference is that $\mathrm{CE}$ is well aware of the critical resource impacts of existing infrastructure of modern societies and their production and consumption patterns. It is the main objective of CE to overcome this impact through a resource-saving and restorative system that re-uses resources as long as possible. Therefore, the impact of resources and the way they are used ("resourceness") needs to be given higher attention.

This leads to the final main difference, which is the concept of "value": In CE, value has an objective aspect in terms of footprints, which sheds a critical light on the SDL-perspective of value as being determined uniquely by the beneficiary (or customer) and is therefore purely subjective.

\section{Integration of the two paradigms and resulting benefits}

In this section I will outline how an integration could be achieved and which benefits could result for both paradigms.

\subsection{Integration}

In section 2.4, I introduced a four-level model that adds to the SDL-core concepts a foundational level 1, i.e. the physical or material infrastructure in order to reflect the massive material, environmental and social impacts that result from the resource-dependency of any economic and societal activity of service-for-service exchange. As pointed out there, while this level is not specific to SDL, it underpins society and the economy in general and any service-for-service exchange. It cannot be ignored due to its importance and huge impacts on the sustainability of society and the economy. A consequence of this extension was the subsequent extension of the SDL-concept of "value" (see 2.4) to reflect the impacts of this material dependency.

The transformation to a CE can only be system-wide, i.e. in principle all social and economic activities need to be examined and re-designed regarding their potential to become increasingly and, finally, fully circular.

To support this transformation, CE provides overall orientation, - i.e. "directionality" - for the institutions, ecosystems and service-for-service exchange instances addressed in SDL. Embedding circular directionality in multiple forms of innovative service provisions and business models, e.g. by applying various "R-strategies" (see 3.2.2), SDL can contribute towards a circular transformation of society and the economy, including of the physical infrastructure, through targeted service interventions that reduce the physical impacts.

Figure 5 shows how the two paradigms can be integrated: Service-for-service exchange, value cocreation, service ecosystems and their supporting institutions that reside on levels 2 to 4 of SDL undergo a fundamental reorientation towards circularity and become thereby instruments in the transition towards circularity. Physical or material infrastructure (level 1) through which most of the ecological impacts are generated will be subject to gradual transformation and service interventions to align increasingly with circularity and sustainability objectives. 


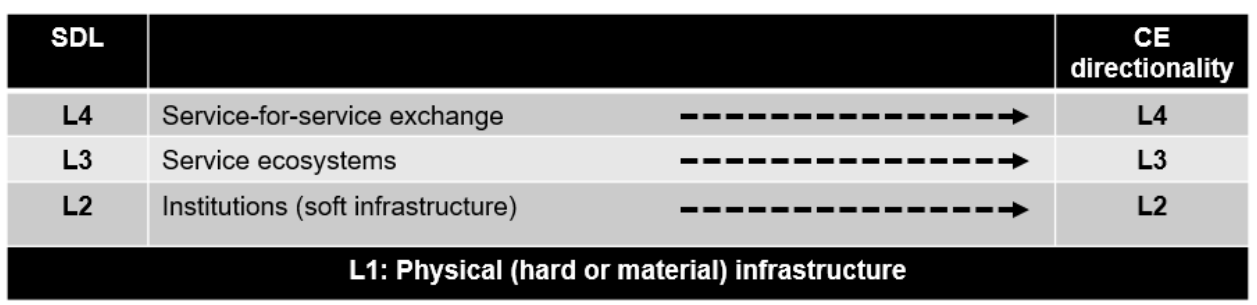

Fig. 5. The relationship between the two paradigms in the integrated model. Source: Author's figure

\subsection{Benefits from an integration for both paradigms}

Both paradigms could gain from an integration as explained below.

\subsubsection{Benefits for SDL}

As the environmental impacts of growing resource use and fossil fuels become ever more obvious, calls to contribute to reducing them are becoming also increasingly dominant. By integrating CE-principles, SDL could engage in elaborating service models, starting from the design of products and processes to business models and specific occupations such as maintenance, repair, re-use, collection, sorting and recycle services that need much higher attention and expansion in a $\mathrm{CE}$. This includes the design of new or modified jobs and the systematic transfer of knowledge about CE at all levels of the educational sector.

To function successfully, CE requires the cooperation of many actors in a product chain [58], but also in the use and after-use phases of products. To bring actors with complementary and specific know-how together and relate their potential service contributions to each other will require specific intermediary service providers that have a holistic knowledge of the potential for circular re-design, are familiar with industry players and are able to perform bridging functions to connect actors as potential cooperation partners in new and emerging ecosystems [59].

Furthermore, SDL could focus specifically on analyzing systems with a view to identifying intervention points in processes and linear supply chains to develop and embed alternative solutions that would reduce resource and energy use, make products more circular, and extend their life span. Further options would be to engage in designing, testing and evaluating different product-as-a-service-models $(\mathrm{PaaS})$ as well as business models around principles of a sharing economy that aim at increasing the intensity of use by sharing goods and facilities between multiple users.

\subsubsection{Benefits for CE}

CE has emerged from a focus on the material economy, studies of resource constraints and environmental implications of the "linear economy". Although more attention is now given to business models and business strategies based on CE principles, the focus on material stocks and flows has remained. While this is justified and reflects the main objectives of $\mathrm{CE}$, service interventions and the re-design of processes and supply chains towards increasing their circularity have so far been given insufficient attention. As shown in Table 4, SDL and CE both distinguish between different and nested levels of systems (micro, meso, macro) that determine and are dependent on each other which all require re-design towards CEobjectives in order to make $\mathrm{CE}$ a reality. As long as the majority of society and the economy continue to adhere to linear operating principles, CE-inspired business models used by some firms or CE-principles applied in the design of some products (e.g. through modular design, repairability, upgradability, recyclability etc.) are insufficient to steer the transition towards a $\mathrm{CE}$ on a large scale.

The core of SDL rests in the objective of value (co-)creation through service for beneficiaries. As became apparent during this analysis, service is always dependent on a material basis which results in the generation of "negative" value or value loss. This realization poses a challenge to the very core of SDL: If value creation can only be achieved by ignoring certain negative aspects resulting from this process, then the possibility of value creating service itself is put into question.

However, by accepting the material dependence of service, SDL can be used to analyze and identify possible service intervention points that may be leveraged for the re-design of processes, the re-building of actor exchange networks and supply chains at all system levels (micro, meso and macro) with the objective to increase their circularity. With such an orientation, SDL can contribute towards reducing the inherent generation of negative value and make progress towards its core objective of value-creation through service.

\section{Conclusions}

A fundamental transformation process towards sustainable societies and circular economy is underway. This transformation requires inter alia support from service initiatives that proactively and explicitly, but also in embedded form, inject circularity principles, methods, techniques, ideas, good practices etc. into the current society and the economy. 
In light of the importance of operant resources (skills, knowledge, competencies etc.) in SDL, a wide range of service opportunities is emerging that support the circularity transition. With its flexible approach, generic concepts and emphasis on value cocreation through multi-actor cooperation and resource integration, SDL is well positioned to act on this opportunity and become an active and constructive participant in this transition,.

Returning to the two research questions formulated in section 1, I conclude that an integration of the two paradigms of SDL and CE is possible. In the process of analyzing core concepts of SDL and developing a pathway for an integration, I suggested to extend the perspective of SDL to cover the physical and material infrastructure which forms the basis of all societal and economic activities and service exchanges. The second consequence was to extend the concept of value in SDL towards a concept with two aspects, one being subjective ("value to beneficiary") and another one objective ("value to society").

Further to the second research question, the integrated model shown in section 5 proposes a re-orientation of SDL, its concepts and approach, towards the circular directionality provided by CE. In this form, CE-principles, instruments, techniques, business and operational models etc. could be embedded in SDL which could become a driver in the transition towards circularity. In my view, both paradigms could benefit from such an integration. CE with its focus on material and resource flows and stocks would benefit from the service ecosystems' view, the dynamic cooperation between different actors that provide service for each other and the concept of value cocreation. SDL would gain from the directionality provided by $\mathrm{CE}$ and from overcoming its current limitations due to omitting material impacts and by considering value as only subjective. An integration could provide SDL with a "sustainability compass" and CE with a framework of service concepts that could help build circular actor networks and ecosystems that have embedded circularity principles at their core and apply them in their day-to-day operations.

\section{References}

1. S. L. Vargo and R. F. Lusch, J. Mark. 68, 1 (2004)

2. O. Furrer, J. K. Kerguignas, C. Delcourt, and D. D. Gremler, J. Serv. Mark. 34, 299 (2020)

3. K. E. Boulding, in Jarrett, H., Ed., Environmental Quality in a Growing Economy, Resources for the Future (Johns Hopkins University Press, Baltimore, 1966), pp. 3-14

4. S. L. Vargo and R. F. Lusch, Ind. Mark. Manag. 37, 254 (2008)

5. S. L. Vargo, in The SAGE Handbook of Service-Dominant Logic (SAGE Publishing, London, Thousand Oaks, New Delhi, Singapore, 2019), pp. xxxvii-xxxvix

6. R. F. Lusch and S. L. Vargo, in The SAGE Handbook of Service-Dominant Logic (SAGE Publishing, London, Thousand Oaks, New Delhi, Singapore, 2019), pp. 3-21

7. S. L. Vargo, J. Bus. Ind. Mark. 24, 373 (2009)

8. R. F. Lusch and S. L. Vargo, Service-Dominant Logic. Premises, Perspectives, Possibilities (Cambridge University Press, Cambridge, 2014)

9. S. L. Vargo and R. F. Lusch, J. Acad. Mark. Sci. 44, 5 (2016)

10. S. L. Vargo and R. F. Lusch, Int. J. Res. Mark. 34, 46 (2017)

11. M. A. Akaka and S. L. Vargo, Inf Syst E-Bus Manage 12, 367 (2014)

12. S. L. Vargo, in The SAGE Handbook of Service-Dominant Logic (SAGE Publishing, London, Thousand Oaks, New Delhi, Singapore, 2019), pp. 720-739

13. J. Chandler and S. L. Vargo, Mark. Theory 1, 35 (n.d.)

14. S. L. Vargo and R. F. Lusch, Ind. Mark. Manag. 40, 181 (2011)

15. S. L. Vargo, P. P. Maglio, and M. A. Akaka, Eur. Manag. J. 26, 145 (2008)

16. S. L. Vargo, M. A. Akaka, and C. M. Vaughan, J. creating value 1 (2017)

17. R. F. Lusch and S. Nambisan, MIS Quaterly 39, (2015)

18. K. Koskela-Huotari, The Evolution of Markets - A Service Ecosystems Perspective, Doctoral thesis, Karlstad University, 2018

19. M. A. Akaka, K. Koskela-Huotari, and S. L. Vargo, in Handbook of Service Science, Volume II, Service Science: Research and Innovations in the Service Economy (Springer Nature Switzerland, 2019), pp. 641-659

20. H. Wieland, F. Polese, S. L. Vargo, and R. F. Lusch, Int. J. Serv. Sci. Manag. Eng. Technol. 3, 12 (2012)

21. J. Gadrey, in The Handbook of Innovation and Services. A Multi-Disciplinary Perspective (Edward Elgar Publishing, Cheltenham, UK, Northampton, USA, 2010), pp. 92-125

22. F. Djellal and F. Gallouj, Service innovation for sustainability: paths for greening through service innovation (HAL archives-ouvertes.fr, 2015)

23. J. E. Fulmer, Infrastruct. Invest. 9, 30 (2009)

24. S. Thacker, D. Adshead, S. Hallegatte, M. Harvey, H. Meller, N. O’Regan, J. Rozenberg, G. Watkins, and J. W. Hall, Nat. Sustain. (2019)

25. UNEP, International Good Practice Recommendations for Sustainable Infrastructure (United Nations Environment Programme, Nairobi, 2021)

26. IPCC, Climate Change 2021. The Physical Basis. Summary for Policymakers. Working Group I Contribution to the Sixth Assessment Report of the IPCC (2021) 
27. IRP, Global Resources Outlook 2019: Natural Resources for the Future We Want (United Nations Environment Programme, 2019)

28. OECD, Global Material Resources Outlook to 2060: Economic Drivers and Environmental Consequences (OECD Publishing, Paris, 2018)

29. P. Dasgupta, The Economics of Biodiversity: The Dasgupta Review. Abridged Version (HM Treasury, London, 2021)

30. UNEP, Global Environment Outlook - GEO 6: Summary for Policymakers (United Nations Environment Programme, Nairobi, 2019)

31. B. D. Matthies, D. D’Amato, S. Berghall, T. Ekholm, H. F. Hoen, J. Holopainen, J. E. Korhonen, K. Lahtinen, O. Mattila, A. Toppinen, L. Valsta, L. Wang, and R. Yousefpour, J. Clean. Prod. 124, 51 (2016)

32. M. Wackernagel and B. Beyers, Ecological Footprint. Managing Our Biocapacity Budget (New Society Publishers, Gabriola Island, Canada, 2019)

33. S. K. Kwan and P. Hottum, Service Science 6, 1 (2014)

34. Oxfam, Confronting Carbon Inequality. Putting Climate Justice at the Heart of the COVID-19 Recovery (Oxfam, 2020)

35. A. L. Fanning, D. W. O’Neill, J. Hickel, and N. Roux, Nat. Sustain. 5, 26 (2022)

36. Circle Economy, The Circularity Gap Report 2022 (Circle Economy, Amsterdam, 2022)

37. W. R. Stahel, Nature 531, 435 (2016)

38. D. W. Pearce and R. K. Turner, Economics of Natural Resources and the Environment (The Johns Hopkins University Press, Baltimore, 1990)

39. S. K. Ghosh (ed.), Circular Economy: Global Perspective (Springer Nature Singapore, 2020)

40. F. Blomsma and G. Brennan, J Ind Ecol 21, 603 (2017)

41. D. Reike, W. J. V. Vermeulen, and S. Witjes, Resour. Conserv. Recycl. 135, 246 (2018)

42. CIRAIG, Circular Economy: A Critical Literature Review of Concepts (CIRAIG, 2015)

43. J. Kirchherr, D. Reike, and M. Hekkert, Resources, Conservation and Recycling 127, 221 (2017)

44. N. Millar, E. McLaughlin, and T. Börger, 158, 11 (2019)

45. H. Corvellec, A. F. Stowell, and N. Johannson, J Ind Ecol 1 (2021)

46. K. Webster, The Circular Economy. A Wealth of Flows, 2nd ed. (Ellen MacArthur Foundation Publishing, Cowes, United Kingdom, 2017)

47. W. R. Stahel, The Circular Economy. A User's Guide (Routledge, London and New York, 2019)

48. P. Ghisellini and S. Ulgiati, in Handbook of Circular Economy (Edward Elgar Publishing, Cheltenham, UK, Northampton, USA, 2020), pp. 491-504

49. D. E. European Commission, Towards a Circular Economy: A Zero Waste Programme for Europe (2014)

50. P. Knight and J. O. Jenkins, J. Clean. Prod. 17, 549 (2009)

51. W. R. Stahel, The Performance Economy, 2nd ed. (Palgrave Macmillan, Houndmills, Basingstoke, and New York, 2010)

52. OECD, Business Models for the Circular Economy. Opportunities and Challenges for Policy (OECD Publishing, Paris, 2019)

53. R. F. Lusch and S. L. Vargo, in The Service-Dominant Logic of Marketing: Dialog, Debate, and Directions. (M. E. Sharpe, Inc., 2006), pp. 406-420

54. R. F. Lusch, S. L. Vargo, and M. O'Brien, J. Retail. 83, 5 (2007)

55. L. A. Bettencourt, R. F. Lusch, and S. L. Vargo, Calif. Manag. Rev. 57, 44 (2014)

56. H. Wieland, N. N. Hartmann, and S. L. Vargo, J. of the Acad. Mark. Sci. 925 (2017)

57. S. L. Vargo, Circular Economy and Sustainability 257 (2021)

58. A.-M. Tillmann, S. Willskytt, D. Böckin, H. André, and M. Ljunggren, in Handbook of the Circular Economy (Edward Elgar Publishing, Cheltenham, UK, Northampton, USA, 2020), pp. 327-342

59. J. Barrie and W. Kanda, in Handbook of the Circular Economy (Edward Elgar Publishing, Cheltenham, UK, Northampton, USA, 2020), pp. 235-249 